\title{
VALUES OF BROAD BAND TURBIDITY COEFFICIENTS IN A MEDITERRANEAN COASTAL SITE
}

\author{
R. PEDRÓS, M. P. UTRILLAS, J. A. MARTÍNEZ-LOZANO ${ }^{\dagger}$ and F. TENA \\ Departamento Termodinámica, Facultat de Física, Universitat de Valencia, 46100 Burjassot, Valencia, Spain
}

Received 14 April 1998; revised version accepted 13 January 1999

Communicated by RICHARD PEREZ

\begin{abstract}
The Angstrom turbidity coefficient, the Linke turbidity factor, and the Unsworth-Monteith coefficient have been determined and analysed based on measurements of normal direct irradiance and global horizontal irradiance taken in Valencia, Spain, between January 1990 and December 1996. The data, which were acquired automatically and continuously, have been filtered to select only those values corresponding to clear sky conditions. To determine the Angstrom turbidity coefficient the method proposed by Louche et al. has been used whilst the expression for $\delta_{\mathrm{CDA}}$ proposed by Kasten was used to obtain the Linke turbidity coefficient. The Angstrom turbidity coefficient showed a minimum in winter with values between 0.06 and 0.12 . It tended to increase in the spring and reach a maximum between 0.22 and 0.29 in summer before falling again in the autumn. The daily and annual evolution of all three coefficients were very similar with correlation coefficients between pairs of them close to 1 . (C) 1999 Elsevier Science Ltd. All rights reserved.
\end{abstract}

\section{INTRODUCTION}

Solar radiation is attenuated when passing through the earth's atmosphere. Radiation extinction is mainly due to scattering by air molecules and aerosol particles, and to absorption by different atmospheric components, such as ozone, water vapour, oxygen, carbon dioxide and others. Some atmospheric components are permanent and almost constant but others, especially aerosols, change from place to place and vary with time. It is known that on clear days aerosols are the atmospheric constituents that cause most attenuation of solar radiation at visible and near-IR wavelengths (Szymber and Sellers, 1985), but because of the variability in aerosol properties, it is difficult to assess their effect on climate. For a full assessment of aerosol characteristics, measurements have to be performed frequently in locations with different aerosol types and in varying meteorological conditions (Kaufman et al., 1994).

When aerosols are present, the atmosphere is considered to be turbid, and the effect that those aerosols produce on solar radiation is known as turbidity. By considering the radiative effects of aerosols, different methods have been developed

Author to whom correspondence should be added. Tel.: +346-386-4300, ext. 3270; fax: +34-6-634-2345; e-mail: jmartine@uv.es to deduce an atmospheric turbidity index capable of explaining the corresponding attenuation of solar radiation. Although accurate spectral observations permit detailed analysis of specific radiative forcing and the impact on climate, systematic spectral measurements are very scarce so the amount of aerosols in the atmosphere is generally represented by broad band turbidity coefficients. These coefficients relate to the reduction at ground level of the extraterrestrial solar irradiance for the whole solar spectrum. The most commonly used coefficients are the Angstrom turbidity coefficient (Angstrom, 1961), the Linke turbidity factor (Linke, 1922, 1929), and the Unsworth-Monteith turbidity coefficient (Unsworth and Monteith, 1972).

The Angstrom turbidity coefficient, $\beta$, is the aerosol optical thickness at $1 \mu \mathrm{m}$ wavelength. For other wavelengths, the aerosol optical thickness is related to the Angstrom turbidity coefficient through the power law relationship proposed by Angstrom

$\delta_{a \lambda}=\beta \lambda^{-\alpha}$

where $\lambda$ is the wavelength expressed in micrometres and the wavelength exponent $\alpha$ is related to the size distribution of the aerosols.

The Angstrom coefficient can be obtained from aerosol spectral transmittances at two wavelengths (Angstrom, 1961) and it seems to be independent 
of the air mass (Grenier et al., 1994). Although the experimental determination of the Angstrom turbidity coefficient should be carried out from spectral measurements of solar radiation, such measurements are usually not available, making it necessary to employ integrated measurements in order to determine its value. Several authors (Louche et al., 1987; Pinazo et al., 1995) have proposed different parameterization models for obtaining $\beta$ from integrated solar irradiance measurements.

The Linke turbidity factor (Linke, 1922, 1929), $T_{\mathrm{L}}$, represents the number of clean dry atmospheres (CDA) that would be necessary to produce the same attenuation of the extraterrestrial radiation that is produced by the real atmosphere. Linke proposes expressing the integrated optical thickness of the clear atmosphere as a product of the optical thickness of the atmosphere without water vapour or aerosols, $\delta_{\mathrm{CDA}}$, and the turbidity factor, $T_{\mathrm{L}}$. So, the direct normal solar irradiance at ground level, $G_{n}$, may be expressed as

$G_{n}=\left(G_{\mathrm{sc}} / \rho^{2}\right) \exp \left(-\delta_{\mathrm{CDA}} T_{\mathrm{L}} m\right)$,

where $G_{\mathrm{sc}}$ is the solar constant, $\rho$ is the relative distance Sun-Earth and $m$ is the relative optical air mass. Different expressions have been proposed for determining the $\delta_{\mathrm{CDA}}$ factor (Louche et al., 1986; Molineaux et al., 1995). Grenier et al. (1994) propose redefining the $\delta_{\mathrm{CDA}}$ value to include the absorbing effect due to the permanent gas components of the atmosphere, considering that such gases are uniformly mixed and that they affect clean and dry atmospheres and turbid atmospheres equally. Recently Kasten (1996a) recalculated the $\delta_{\mathrm{CDA}}$ value employing the most recently published spectral data.

The Unsworth-Monteith turbidity coefficient (Unsworth and Monteith, 1972), $T_{\mathrm{U}}$, represents the number of clean dry atmospheres which would produce the same attenuation as the actual atmosphere containing water vapour and aerosols. Unsworth and Monteith, using experimental irradiance measurements of a clean atmosphere, express

$G_{n \lambda}=G_{n \lambda}^{*} \exp \left(-T_{\mathrm{U \lambda}} m\right)$,

where $G_{n \lambda}^{*}$ means the irradiance of an aerosol free atmosphere, and $\exp \left(-T_{\mathrm{U} \lambda} m\right)$ represents an aerosol spectral transmittance coefficient. Considering the definition of the integrated total optical thickness, it is possible to write an integrated expression of $T_{\mathrm{U}}$, similar to the expression for $T_{\mathrm{L}}$, obtaining
$T_{\mathrm{U}}=-\frac{1}{m} \ln \left(\frac{G_{n}}{G_{n}^{*}}\right)$.

Both Linke and Unsworth-Monteith coefficients refer to the whole spectrum, which includes water vapour and aerosol effects. The main difference between these parameters is in the attenuation of solar rays produced by the water vapour content. As Gueymard (1996) suggests, the $T_{\mathrm{L}}$ coefficient is not a pure turbidity coefficient because it also incorporates the water vapour and $\mathrm{NO}_{2}$ optical depths. Nevertheless it may be useful when there are no data on precipitable water making it difficult to obtain all the other coefficients.

\section{EXPERIMENTAL SET-UP AND METHODOLOGY}

The measurements were taken on the terrace of the Faculty of Physics, Valencia University, Spain, at $40 \mathrm{~m}$ above sea level at a latitude of $39.5^{\circ} \mathrm{N}$. The obstructions above the horizon were less than $4^{\circ}$, except in a small zone to the north-west. An Eppley Normal Incidence Pyrheliometer (NIP) and a Kipp-Zonen CM-6 Pyranometer were used to measure normal direct irradiance and global horizontal irradiance, respectively. The measurements were recorded continuously, and average values were stored in a datalogger every $10 \mathrm{~min}$. The instrumentation used to record integrated radiation constitutes part of a solar radiation measuring station described in a previous paper by Utrillas et al. (1991). Data analysis is based on the irradiance measurements made in the period January 1990 to December 1996. In this database there exist several periods of missing data, most of them due to calibration. In addition, there are two more relevant periods with no data available (in the years 1995 and 1996). During these periods, work was being done to waterproof the building in the place where the instruments were mounted. The original data, corresponding to mean values of $10-\mathrm{min}$ registers, have been considered as instantaneous (irradiance, $\mathrm{W} / \mathrm{m}^{2}$ ), and from these data instantaneous values of the turbidity coefficients have been deduced. The water vapour content was estimated from relative humidity measurements provided by the Spanish Institute of Meteorology (INM).

Since turbidity indices are defined for clear sky conditions, the registered data have been automatically filtered in order to select only those fulfilling this condition. The criteria used to identify clear sky conditions and to avoid threshold radiation values were based on a zenith angle 
independent clearness index $k_{t}^{\prime}$ (Perez et al., 1990). $k_{t}^{\prime}$ is obtained by normalizing the clearness index $k_{t}$ (defined as the ratio of earth's surface global over extraterrestrial global irradiance) to one for a relative air mass of one. Perez et al. (1990) use the Kasten's pyrheliometric formula for such normalization (Kasten, 1996b). According to this formula the zenith angle-independent $k_{t}^{\prime}$ is defined as

$k_{t}^{\prime}=k_{t} /[1.031 \times \exp (-1.4 /(0.9+9.4 / m)+0.1]$.

This criterium does not mean a completely cloudfree atmosphere because the data could be slightly contaminated by thin clouds, which neither noticeably reduce the sunshine hours nor $k_{t}^{\prime}$. Nevertheless it presents the advantage of using a single parameter to select the data. Moreover is easy to use it automatically, and avoids the dependence on the visual cloud observations.

The condition imposed on the measured data was $k_{t}^{\prime}>0.7$, according to Molineaux et al. (1995). Using these criteria, 37853 instantaneous data sets corresponding to clear sky conditions are available. These data sets constitute $23.7 \%$ of the total valid values (159413) recorded during the period of 7 years. The number of clear sky values is not so high bearing in mind the accumulated insolation registered yearly at Valencia, which is greater than $2600 \mathrm{~h}$ according to the last reference year (Martínez-Lozano and Utrillas, 1994). Also, the values corresponding to very low solar heights $\left(<5^{\circ}\right)$ have been removed, because such data are outside the range of conditions for which most of the methods considered are applicable (Molineaux et al., 1995).

Although turbidity values only have a physical meaning if instantaneous values are considered, the mean values corresponding to longer intervals, usually a day, are also widely used. Once the instantaneous values of the turbidity coefficients are obtained, hourly and daily values are easily determined. For hourly values, only hours with all six 10-min data have been considered. The daily values have been obtained directly from the instantaneous data so as to be able to consider the data corresponding to the beginning and to the end of the corresponding day. Only those days for which at least $50 \%$ of the instantaneous values satisfied the clear sky criteria were considered for calculating daily average values.

To analyse the errors of the experimental measurements and of the indirect data obtained from them, the following assumptions were made.
1. The error assigned to the measured data coincided with the precision of different instruments employed: pyrheliometer for the direct irradiance $(3 \%)$ and pyranometer for the global irradiance on a horizontal surface $(5 \%)$.

2. The error due to the parameterised geometrical factors were as suggested by the corresponding author. For example, the optical air mass, deduced from the Kasten and Young (1989) expression, had a $0.1 \%$ error.

3. In the mathematical expressions, such as the calculation of the transmittances and of the intermediate variables of the Louche method, the error propagation method was appropriate.

\section{RESULTS AND DISCUSSION}

\subsection{Angstrom $\beta$ coefficient}

The method of Louche et al. (1987) was employed to determine the Angstrom turbidity coefficient. It is based on the expression

$G_{n}=k G_{0 n} \tau_{\mathrm{a}} \tau_{\mathrm{R}} \tau_{\mathrm{g}} \tau_{\mathrm{w}} \tau_{\mathrm{oz}}$

where $G_{0 n}$ is the integrated extraterrestrial irradiance at normal incidence $\left(G_{\mathrm{sc}} / \rho^{2}\right)$ and $k$ is a factor whose value depends on the extraterrestrial spectrum used in the calculations. In this paper, the Froelich and Wehrly model (Riordan, 1987) has been used. This spectrum is integrated within the spectral band 0.285 to $2.8 \mu \mathrm{m}$ (corresponding to the pyrheliometric transmittance). The value of $k$ according to this spectrum is 0.9712 .

The transmittances due to the absorption of the different atmospheric constituents were obtained from the parameterization developed by Bird and Riordan (1984). For the transmittance due to atmospheric aerosols the expression of Mächler (Iqbal, 1983) was used. Combining these models and setting $\alpha$ equal to the constant value of 1.3 proposed by Mächler (Iqbal, 1983), the $\beta$ coefficient can be expressed as

$\beta=\frac{1}{m D} \ln \left(\frac{C}{A-B}\right)$

where

$A=\frac{G_{n}}{k G_{0 n} \tau_{\mathrm{R}} \tau_{\mathrm{g}} \tau_{\mathrm{ws}} \tau_{\mathrm{oz}}}$

$B=0.12445 \alpha-0.0162$

$C=1.003-0.125 \alpha$

$D=1.089 \alpha+0.5123$ 
Considering that the composition of the atmosphere is quite steady, the water content, $w$, becomes the parameter with the highest influence on $\beta$. Fig. 1 represents the Angstrom coefficient $\beta$ values against the optical air mass for a specific day $(09 / 09 / 94)$ and for different values of the water content. The variations of the coefficient $\beta$ may be near to $20 \%$ in some cases. In case there are no available experimental data for $w$, the following polynomial fitting (Pedrós, 1997) is used:

$$
\begin{aligned}
w_{\mathrm{p}}(\mathrm{cm})= & 1.6114-0.00455 d+0.000152 d^{2} \\
& -4.09 \times 10^{-7} d^{3},
\end{aligned}
$$

where $d$ is the Julian day. Eq. (11) has been obtained after analyzing all the available data corresponding to the whole period of measurement.

To analyse the error introduced by this approximation, data corresponding to 1994 have been used. The relations obtained between the $\beta$ parameter corresponding to the polynomic values, $w_{\mathrm{p}}$, and the real ones, $w_{\mathrm{r}}$, were the following.

- Instantaneous values

$$
\begin{aligned}
& \beta\left(w_{\mathrm{p}}\right)=-0.002+1.005 \beta\left(w_{\mathrm{r}}\right) \\
& \left(r^{2}=0.998\right)(N=5011)
\end{aligned}
$$

- Hourly values

$$
\begin{aligned}
& \beta\left(w_{\mathrm{p}}\right)=-0.001+1.004 \beta\left(w_{\mathrm{r}}\right) \\
& \left(r^{2}=0.998\right)(N=1053)
\end{aligned}
$$

- Daily values

$$
\begin{aligned}
& \beta\left(w_{\mathrm{p}}\right)=-0.002+1.008 \beta\left(w_{\mathrm{r}}\right) \\
& \left(r^{2}=0.998\right)(N=163)
\end{aligned}
$$

Considering the high correlation obtained, it seems reasonable to employ $w_{\mathrm{p}}$ whenever experimental values of $w$ are not available.

Instantaneous values of the Angstrom turbidity coefficient for the 7 years considered have been obtained. In Table 1 a summary of those values corresponding to an average year is presented. Maximum, minimum and mean values are included, as well as the standard deviation of the mean. The mean instantaneous values are nearer to the minima than to the maxima, meaning that the maximum values (about 0.5 for the summer months) do not represent the atmospheric characteristics of Valencia, and that any conclusion derived from them must be considered with caution. This is not the case for the minimum values which are more persistent. Hourly and daily values have also been generated from the instantaneous values. These values are similar to

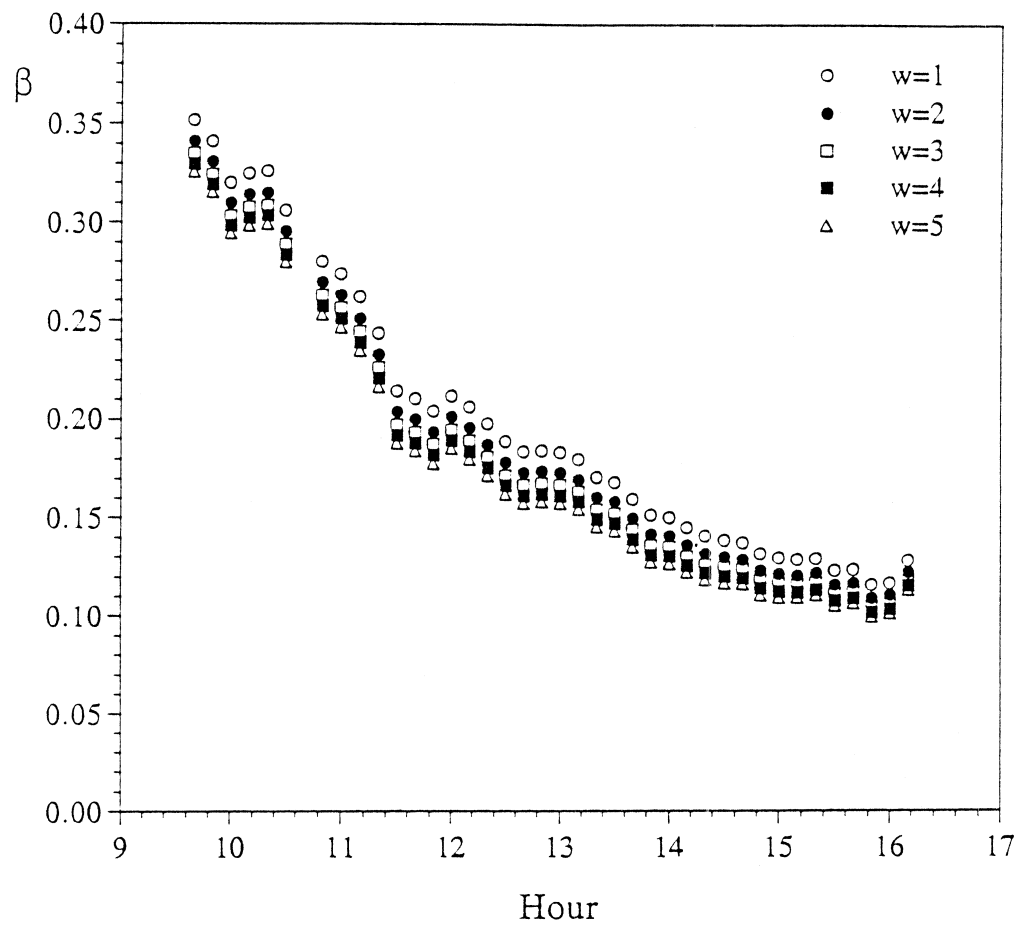

Fig. 1. Daily evolution of the coefficient $\beta$ as a function of the water vapour content in the atmosphere. Day 09/09/94. 
Table 1. Instantaneous values of the Angstrom turbidity coefficient, $\beta$, for an average year

\begin{tabular}{ccccc}
\hline Month & Maximum & Minimum & Mean & $\sigma$ \\
\hline January & 0.22 & 0.02 & 0.08 & 0.03 \\
February & 0.30 & 0.01 & 0.09 & 0.05 \\
March & 0.33 & 0.04 & 0.13 & 0.06 \\
April & 0.45 & 0.04 & 0.14 & 0.08 \\
May & 0.48 & 0.06 & 0.16 & 0.07 \\
June & 0.48 & 0.08 & 0.20 & 0.08 \\
July & 0.47 & 0.08 & 0.21 & 0.07 \\
August & 0.41 & 0.07 & 0.20 & 0.07 \\
September & 0.39 & 0.05 & 0.17 & 0.07 \\
October & 0.31 & 0.04 & 0.08 & 0.05 \\
November & 0.22 & 0.04 & 0.09 & 0.04 \\
December & 0.20 & 0.04 & 0.09 & 0.04 \\
\hline
\end{tabular}

the instantaneous ones. The mean instantaneous values oscillate between 0.05 (November, 1990) and 0.29 (July, 1994) while if mean daily values are considered, the extreme values are 0.06 (January, 1994 and February, 1996) and 0.29 (July, 1994). Fig. 2 shows the temporal evolution of the monthly mean daily values of $\beta$ for the 7 -year period. The annual cycle described by other investigators (Karalis, 1976; Katz et al., 1982; Louche et al., 1987; Abdelrahman et al., 1988; Canada et al., 1993; Jacovides and Karalis, 1996) is observable with a minimum in the winter with values between 0.06 and 0.12 , increased turbidity during the spring, a maximum in the summer with values between 0.22 and 0.29 and a decrease in autumn.
The turbidity increase in spring may be explained by the rapid heating of the ground, causing a more effective transport of dust and combustion products from the ground to the atmosphere. This effect is lower in the winter, so the aerosol content is smaller. In summer the turbidity reaches a maximum due to several factors such as infrequent rain, high temperatures that increase the atmospheric convection and thus the particle flux from the ground, SE and SW winds with air streams from the Sahara that are humid (having crossed the Mediterranean Sea) and turbid (because of the desert dust), atmospheric pollution from the city of Valencia, exacerbated by the high pressures and the high temperatures of the summer period. Furthermore, the humidity due to the influence of the nearby Mediterranean Sea and the high solar energy received in this period produces the formation of microscopic water droplets that capture hygroscopic salts so increasing the turbidity. In the autumn the frequent rains clean the atmosphere and the turbidity decreases consequently to the winter minimum.

The daily evolution of the $\beta$ values is represented in Fig. 3 for the four seasons. The associated errors, about $30 \%$, may induce overlapping values, especially in autumn and winter. The turbidity increases during the morning reaching a maximum at about 11:00 $\mathrm{h}$ in spring and summer

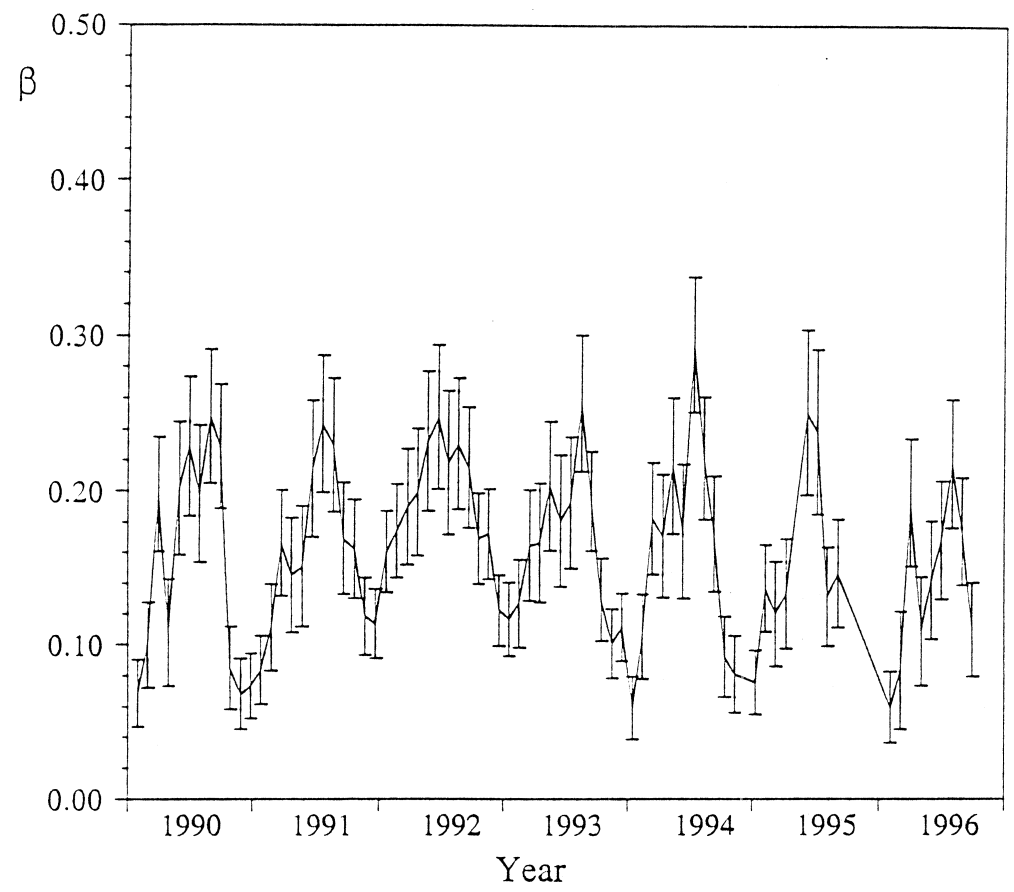

Fig. 2. Time evolution of the monthly mean daily values of coefficient $\beta$ (1990-1996). 


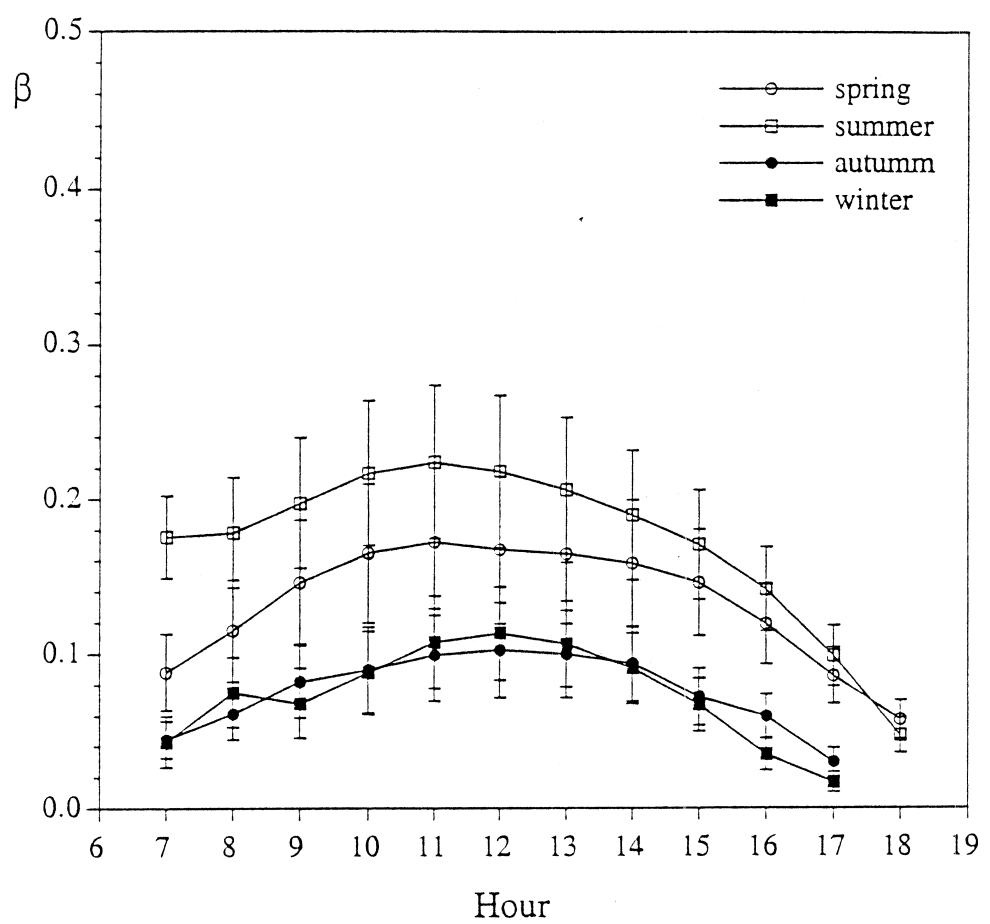

Fig. 3. Seasonal daily evolution of the hourly values of the coefficient $\beta$ (1990-1996).

and at 12:00 $\mathrm{h}$ in autumn and winter. In the afternoon the turbidity decreases, reaching a minimum value at the end of the day that is lower than at the beginning of the day.

\subsection{Linke coefficient, $T_{L}$}

The Linke turbidity coefficient was determined using the expression proposed by Kasten (1996a) for $\delta_{\mathrm{CDA}}$

$$
\begin{aligned}
\delta_{\mathrm{CDA}}= & \left(6.6296+1.7513 m-0.1202 m^{2}\right. \\
& \left.+0.0065 m^{3}-0.00013 m^{4}\right)^{-1} .
\end{aligned}
$$

The instantaneous value of the turbidity coefficient is determined with the expression

$T_{\mathrm{L}}=\frac{1}{m \delta_{\mathrm{CDA}}} \ln \left(\frac{G_{\mathrm{sc}}}{\rho^{2} G_{n}}\right)$.

From this expression, and the 10-min values of direct irradiance, the instantaneous values of $T_{\mathrm{L}}$ have been determined for the whole measurement period, from which the hourly and daily values have been generated. Table 2 presents a summary of the instantaneous values corresponding to an average year. The evolution of the Linke turbidity coefficient throughout a year is similar to that corresponding to the Angstrom coefficient.

\subsection{Unsworth-Monteith coefficient, $T_{U}$}

For the determination of the Unsworth-Monteith coefficient, the value of $G_{n}^{*}$ is deduced from the expression

$G_{n}^{*}=G_{0 n} \tau_{\mathrm{R}} \tau_{\mathrm{g}} \tau_{\mathrm{w}} \tau_{\mathrm{oz}}$.

Then $T_{\mathrm{U}}$ may be expressed as

$T_{\mathrm{U}}=-\frac{1}{m} \ln \left(\frac{G_{n}}{\left(G_{\mathrm{sc}} / \rho^{2}\right) \tau_{\mathrm{R}} \tau_{\mathrm{g}} \tau_{\mathrm{w}} \tau_{\mathrm{oz}}}\right)$

The parametric expressions proposed by Kambezidis et al. (1993) have been used for determining the different transmittances of expression (18).

In Table 3 the instantaneous values of the

Table 2. Instantaneous values of the Linke turbidity coefficient, $T_{\mathrm{L}}$, for an average year

\begin{tabular}{ccccc}
\hline Month & Maximum & Minimum & Mean & $\sigma$ \\
\hline January & 4.9 & 1.7 & 2.9 & 0.5 \\
February & 5.9 & 1.7 & 3.1 & 0.8 \\
March & 6.2 & 2.3 & 3.6 & 0.9 \\
April & 7.6 & 2.3 & 3.7 & 1.0 \\
May & 8.0 & 2.6 & 4.1 & 0.9 \\
June & 8.0 & 2.9 & 4.6 & 1.0 \\
July & 7.8 & 3.0 & 4.7 & 0.9 \\
August & 7.2 & 2.9 & 4.5 & 0.9 \\
September & 6.9 & 2.6 & 4.1 & 1.0 \\
October & 5.9 & 2.3 & 3.2 & 0.7 \\
November & 4.8 & 2.2 & 2.9 & 0.5 \\
December & 4.6 & 2.3 & 3.1 & 0.6 \\
& & & &
\end{tabular}


Table 3. Instantaneous values of the Unsworth-Monteith turbidity coefficient, $T_{\mathrm{U}}$, for an average year

\begin{tabular}{ccccc}
\hline Month & Maximum & Minimum & Mean & $\sigma$ \\
\hline January & 0.34 & 0.04 & 0.13 & 0.05 \\
February & 0.46 & 0.02 & 0.15 & 0.08 \\
March & 0.51 & 0.07 & 0.21 & 0.10 \\
April & 0.68 & 0.07 & 0.22 & 0.12 \\
May & 0.74 & 0.10 & 0.26 & 0.11 \\
June & 0.74 & 0.13 & 0.32 & 0.12 \\
July & 0.71 & 0.13 & 0.33 & 0.11 \\
August & 0.63 & 0.12 & 0.32 & 0.10 \\
September & 0.59 & 0.09 & 0.27 & 0.11 \\
October & 0.47 & 0.07 & 0.17 & 0.07 \\
November & 0.34 & 0.07 & 0.13 & 0.05 \\
December & 0.31 & 0.07 & 0.15 & 0.05 \\
\hline
\end{tabular}

Unsworth-Monteith coefficient for an average year are summarised. Again the turbidity is lower in the winter than in the summer.

The daily evolution of monthly mean hourly values for the $T_{\mathrm{L}}$ and $T_{\mathrm{U}}$ coefficients is similar to that presented in Fig. 3 for the $\beta$ coefficient. Fig. 4 shows the yearly evolution of monthly daily values for the three turbidity coefficients. It can be observed that the three curves follow similar trends. For the sake of clarity, the error bars have not been included in the figure.

Figs. 5 and 6 represent the instantaneous values of the three turbidity coefficients considered above, corresponding to 2 days with high and low atmospheric turbidity, respectively. The errors are also shown. Fig. 5 represents a typical summer day $(15 / 07 / 93)$ and Fig. 6 a typical winter day $(07 / 01 / 93)$. It may be observed that the daily evolution of the three coefficients is quite similar.

\subsection{Correlation between the different broad band turbidity coefficients}

As it can be observed in the above results, both daily and yearly evolutions of the different turbidity coefficients are very similar. Accordingly a simple correlation between them has been made. The characteristics of these correlations are presented in Table 4. In general the correlations improved with increasing time periods because of smoothing through aggregation. The correlation between $\beta$ and the Linke and Unsworth-Monteith coefficients, with a similar physical meaning, is very near unity.

Several authors have established similar correlations using data measured at other locations. In particular, Jacovides and Karalis (1996) and Kambezidis et al. (1993) have studied the turbidity coefficients for Athens, a site with climatic characteristics similar to those found at Valencia. A comparison between the results of the present work with those obtained from daily values registered at Athens shows that, although the linear regression coefficients are quite similar for the $\beta-T_{\mathrm{U}}$ fittings (with deviations lower than $3 \%$ ), those corresponding to the linear regression involving the Linke turbidity coefficient have

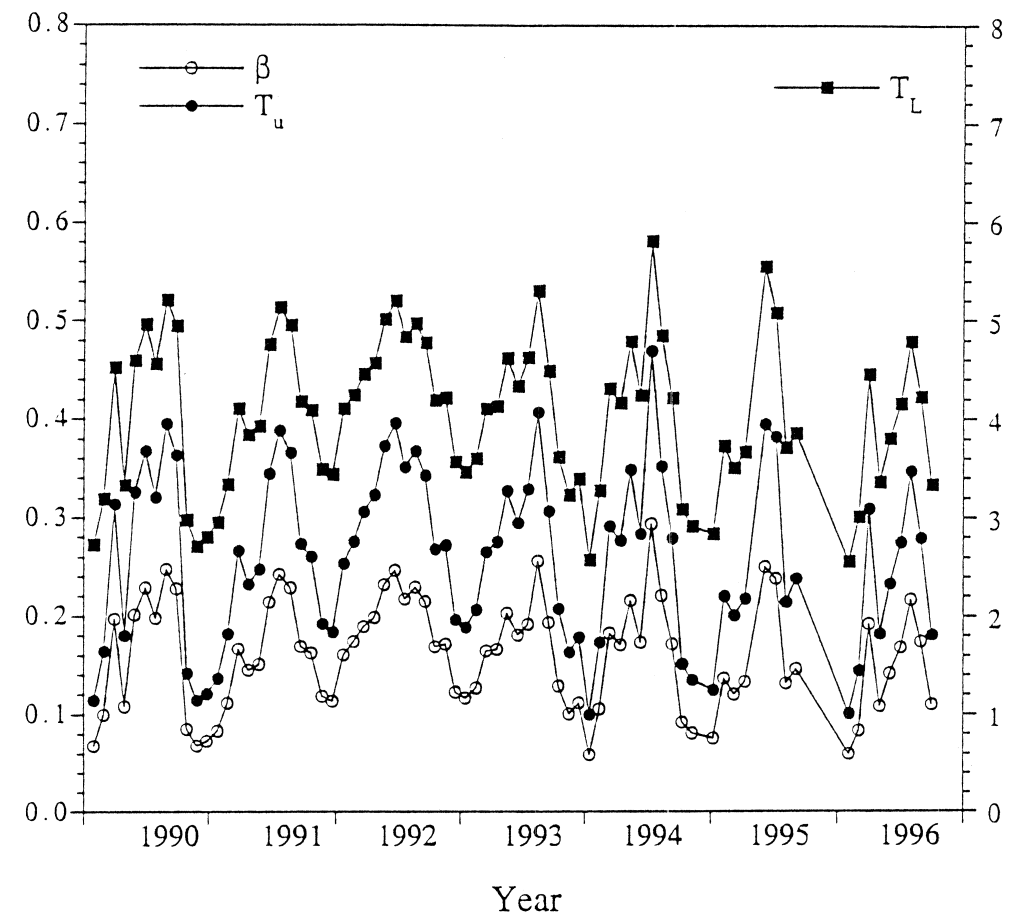

Fig. 4. Time evolution of the monthly mean daily values of coefficients $\beta, T_{\mathrm{L}}$ and $T_{\mathrm{U}}$ (1990-1996). 


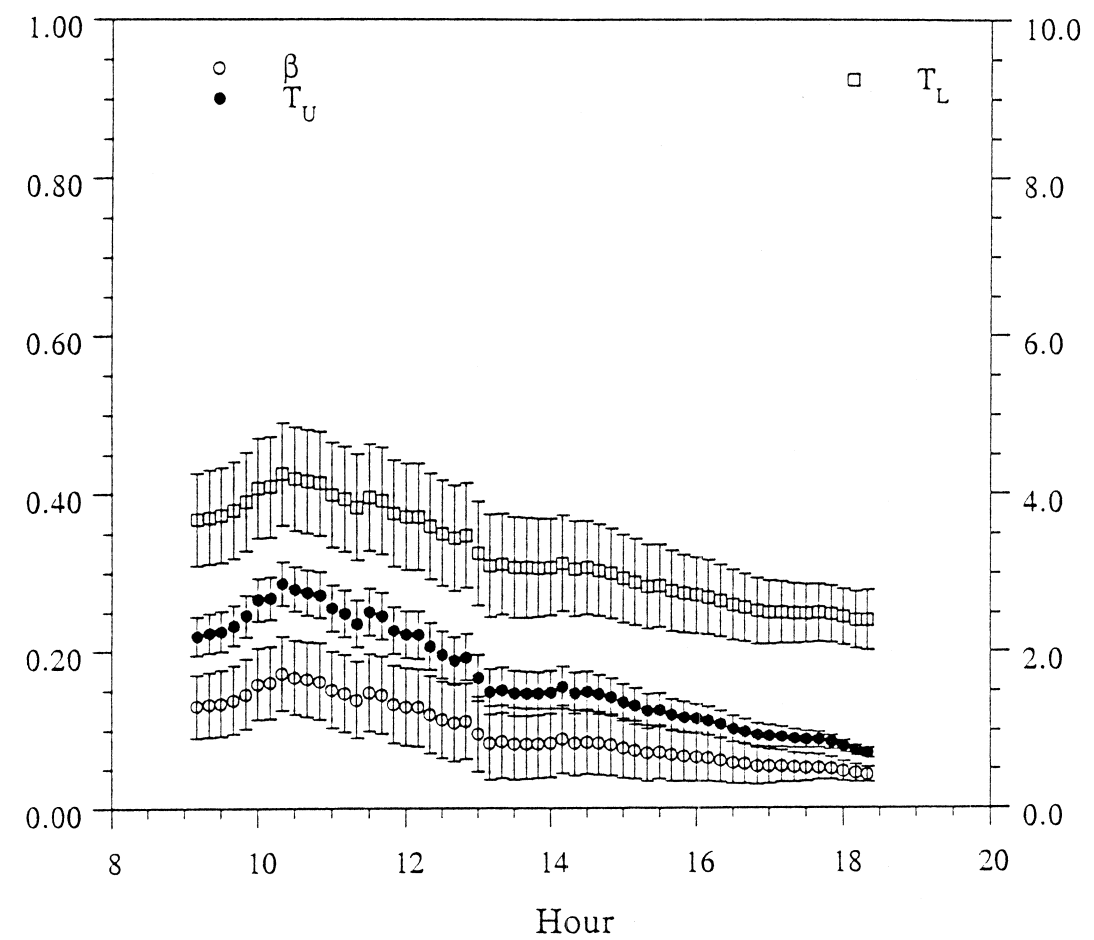

Fig. 5. Daily evolution of the different turbidity coefficients during a summer day (15/07/93).

noticeable deviations (above 20\%). Nevertheless, since the configuration of the two data bases has not been established in the same way and the criteria used to identify clear-sky conditions are also different, the results cannot be compared directly.

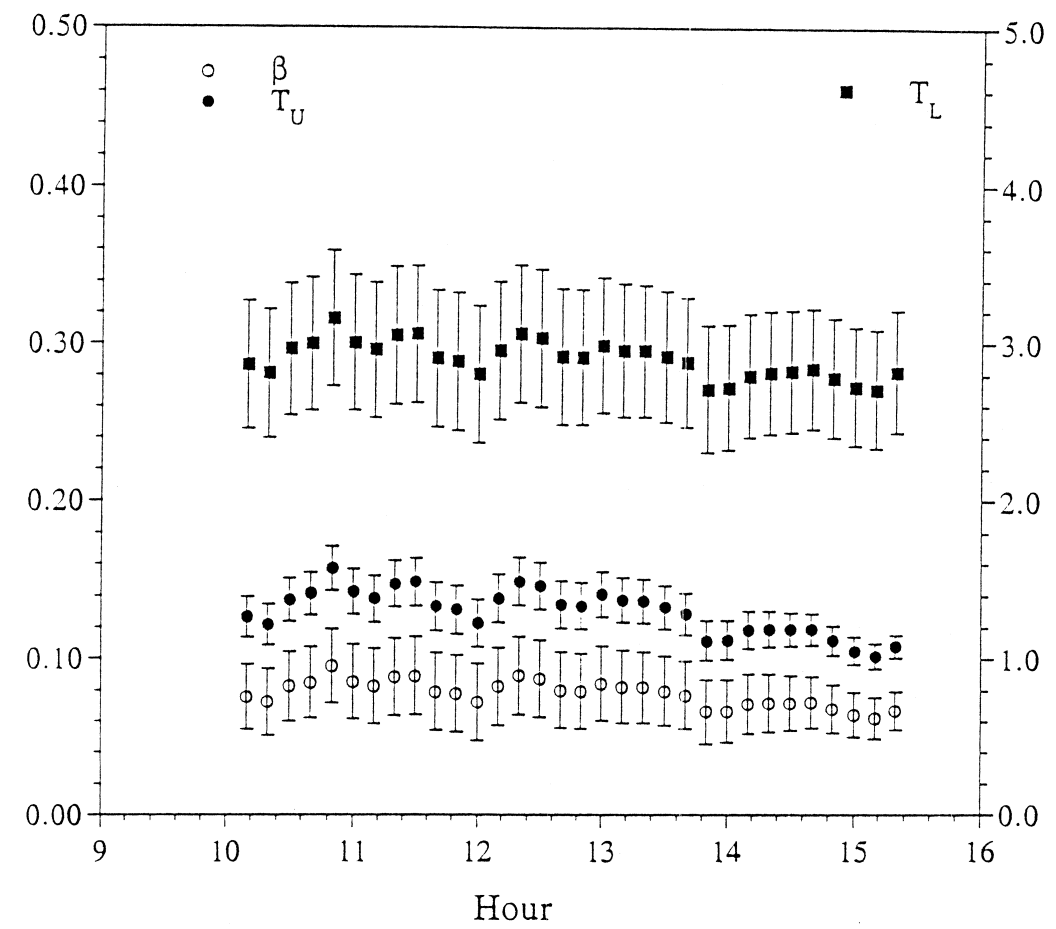

Fig. 6. Daily evolution of the different turbidity coefficients during a winter day $(07 / 01 / 93)$. 
Table 4. Fitting parameters for the linear regression between the three turbidity coefficients $\beta, T_{\mathrm{L}}$ and $T_{\mathrm{U}}$

\begin{tabular}{cccc}
\hline & $\varepsilon$ (slope) & $\varepsilon$ (intercept) & $r$ \\
\hline Instantaneous values & & & \\
$T_{\mathrm{L}}=13.53 \beta+1.87$ & 0.01 & 0.03 & 0.99 \\
$T_{\mathrm{U}}=1.543 \beta+0.023$ & 0.001 & 0.002 & 0.99 \\
$T_{\mathrm{L}}=8.76 T_{\mathrm{U}}+1.75$ & 0.02 & 0.02 & 0.99 \\
Hourly values & & & \\
$T_{\mathrm{L}}=13.73 \beta+1.82$ & 0.02 & 0.06 & 0.99 \\
$T_{\mathrm{U}}=1.537 \beta+0.013$ & 0.002 & 0.004 & 0.99 \\
$T_{\mathrm{L}}=8.729 T_{\mathrm{U}}+1.77$ & 0.04 & 0.04 & 0.99 \\
Daily values & & & \\
$T_{\mathrm{L}}=13.39 \beta+1.88$ & 0.06 & 0.18 & 0.99 \\
$T_{\mathrm{U}}=1.532 \beta+0.014$ & 0.006 & 0.002 & 0.99 \\
$T_{\mathrm{L}}=8.73 T_{\mathrm{U}}+1.76$ & 0.07 & 0.12 & 0.99 \\
\hline
\end{tabular}

\section{CONCLUSIONS}

From integrated irradiance values corresponding to 7 years of data, an analysis of the turbidity coefficients of Angstrom $(\beta)$ (as obtained by the Louche method), Linke $\left(T_{\mathrm{L}}\right)$ and Unsworth-Monteith $\left(T_{\mathrm{U}}\right)$ has been made.

Generally the values of all the considered turbidity coefficients have a minimum in the winter and grow progressively, reaching a maximum in the summer. The summer values are at least twice as high as the winter ones. The morning turbidity values are higher than the afternoon ones, and all three turbidity coefficients vary in a similar manner throughout the day. The correlation between the coefficients is very good with correlation coefficients near to unity.

\section{NOMENCLATURE}

$\alpha \quad$ Angstrom wavelength exponent

$\beta \quad$ Angstrom turbidity coefficient

$\delta_{a \lambda} \quad$ spectral aerosol optical thickness

$\delta_{\mathrm{CDA}} \quad$ integrated optical thickness for a clean dry atmosphere

$\lambda \quad$ wavelength $(\mu \mathrm{m})$

$\rho \quad$ Sun-Earth relative distance

$\tau_{\mathrm{g}} \quad$ atmospheric transmittance for absorption by atmospheric mixed gases

$\tau_{\mathrm{oz}} \quad$ atmospheric transmittance for absorption by ozone

$\tau_{\mathrm{R}} \quad$ atmospheric transmittance for molecular scattering

$\tau_{\mathrm{a}} \quad$ atmospheric transmittance for aerosols

$\tau_{\mathrm{w}} \quad$ atmospheric transmittance for absorption by water vapour

$k_{t} \quad$ clearness index

$k_{t}^{\prime} \quad$ zenith angle independent clearness index

$m \quad$ relative optical air mass

w water vapour content $(\mathrm{cm})$

$G_{n \lambda}^{*} \quad$ monochromatic normal beam irradiance for an aerosol free atmosphere $\left(\mathrm{Wm}^{-2} \mu \mathrm{m}^{-1}\right)$

$G_{n \lambda} \quad$ monochromatic normal beam irradiance $\left(\mathrm{Wm}^{-2}\right.$ $\mu \mathrm{m}^{-1}$ )

$G_{0 n} \quad$ integrated extraterrestrial normal beam irradiance $\left(\mathrm{Wm}^{-2}\right)$

$G_{n}^{*} \quad$ integrated extraterrestrial normal beam irradiance for an aerosol free atmosphere $\left(\mathrm{Wm}^{-2}\right)$
$G_{n} \quad$ integrated normal beam irradiance $\left(\mathrm{Wm}^{-2}\right)$

$G_{\text {sc }} \quad$ solar constant $\left(\mathrm{Wm}^{-2}\right)$

$T_{\mathrm{L}} \quad$ Linke turbidity factor

$T_{\mathrm{U}} \quad$ Unsworth-Monteith coefficient

\section{REFERENCES}

Abdelrahman M. A., Said S. A. H. and Shiaub A. N. (1988) Comparison between atmospheric turbidity coefficients of desert and temperate climates. Solar Energy 40(3), 219225.

Angstrom A. (1961) Techniques of determining the turbidity of the atmosphere. Tellus 13, 214-223.

Bird R. E. and Riordan C. (1984) A simple solar spectral model for direct and diffuse irradiance on horizontal and tilted planes at the earth's surface for cloudless atmospheres. SERI/TR-215-2436, Golden, CO, Solar Energy Research Institute.

Canada J., Pinazo J. M. and Bosca J. V. (1993) Determination of Ångström turbidity coefficient at Valencia. Renewable Energy 3, 621-626.

Grenier J. C., De la Casinière A. and Cabot T. (1994) A spectral model of Linke's turbidity factor and its experimental implications. Solar Energy 52, 303-313.

Gueymard, C. A. (1996) Turbidity determination from broadband irradiance measurements: a detailed multi-coefficient approach. FSEC-PF-311-96. Florida Solar Energy Center, Co, Florida.

Iqbal M. (1983). An Introduction To Solar Radiation, Academic Press, New York.

Jacovides C. P. and Karalis J. D. (1996) Broad-band turbidity parameters and spectral band resolution of solar radiation for the period 1954-91, in Athens, Greece. Int. J. Climatol. 16, 229-242.

Kambezidis H. D., Founda D. H. and Papanikolaou N. S. (1993) Linke and Unsworth-Monteith turbidity parameters in Athens. O. J. R. Meteorol. Soc. 119, 367-374.

Karalis J. D. (1976) The turbidity parameters in Athens. Arch Met. Geoph. Brookl. Ser. B. 24, 25-34.

Kasten F. (1996a) A new table and approximate formula for relative optical air mass. Arch. Meteorol. Geophys. Bioklimatol. Ser. B14, 206-233.

Kasten F. (1996b) The Linke turbidity factor based on improved values of the integral Rayleigh optical thickness. Solar Energy 56(3), 239-244.

Kasten F. and Young A. T. (1989) Revised optical air mass tables and approximation formula. Appl. Optics 28, 47354738

Katz M., Baille A. and Mermier M. (1982) Atmospheric turbidity in a semirural site II. Solar Energy 28(4), 329_ 334.

Kaufman Y. J., Gitelson A., Karnieli A., Ganor E., Fraser R. S., Nakajima T., Mattoo S. and Holben B. N. (1994) Size distribution and scattering phase function of aerosol particles retrieved from sky brightness measurements. $J$. Geophys. Res. 99, 10341-10356.

Linke F. (1922) Transmission koefficient und trubungsfaktor. Beitr. Phys. Frei Atmos. 10, 91-103.

Linke F. (1929) Messungen der Sonnestrahlung beiuvier Freiballonfahrten. Beitr. Phys. Frei Atmos. 15, 176-185.

Louche A., Maurel M., Simonnot O., Peri G. and Iqbal M. (1987) Determination of Ångström's turbidity coefficient from direct solar irradiance measurements. Solar Energy 38, 89-96.

Louche A., Peri G. and Iqbal M. (1986) An analysis of Linke turbidity factor. Solar Energy 37, 393-396.

Martínez-Lozano J. A. and Utrillas P. (1994) Insolación y nubosidad. In En Atlas Climático De La Comunidad Valenciana (1961-1990), Perez Cuevas A. J. (Ed.), C.O.P.U.T., Generalitat Valenciana (in Spanish).

Molineaux B., Ineichein P. and Delaunay J. J. (1995) Direct luminous efficacy and atmospheric turbidity: improving model performance. Solar Energy 55(2), 125-137. 
Pedrós, R. (1997) Estudio de los coeficientes de turbiedad de la atmósfera. Tesis de Licenciatura, Universidad de Valencia (in Spanish).

Perez R., Ineichen P., Seals R. and Zelenka A. (1990) Making full use of the clearness index for parameterizing hourly insolation conditions. Solar Energy 45, 11-114.

Pinazo J. M., Cañada J. and Bosca J. V. (1995) A new method to determine Angstrom turbidity coefficient: its application for Valencia. Solar Energy 54, 219-226.

Riordan, C. (1987) Extraterrestrial spectral solar irradiance data for modelling spectral solar irradiance at the earth surface. SERI/TR-215-2921. Golden CO, Solar Energy Research.

Szymber R. J. and Sellers W. D. (1985) Atmospheric turbidity at Tucson, Arizona, 1956-83: variations and their causes. $J$. Climate Appl. Meteorol. 24, 725-735.

Unsworth M. H. and Monteith J. L. (1972) Aerosol and solar radiation in Britain. Q. J. R. Meteorol. Soc. 98, 778-797. Utrillas M. P., Martinez-Lozano J. A. and Casanovas A. J. (1991) Comparison of models for estimating solar irradiation on vertical surfaces at Valencia, Spain. Solar Energy 47, 223-229. 